\title{
Heterogeneity of signal transduction at the subcellular level: microsphere-based focal EGF receptor activation and stimulation of Shc translocation
}

\author{
Roland Brock* and Thomas M. Jovin‡ \\ Department of Molecular Biology, Max Planck Institute for Biophysical Chemistry, Am Fassberg 11, D-37077 Göttingen, Germany \\ *Present address: Institute of Organic Chemistry, University of Tübingen, Auf der Morgenstelle 18, 72076 Tübingen, Germany (e-mail: roland.brock@uni-tuebingen.de) \\ ‡Author for correspondence (e-mail: tjovin@mpc186.mpibpc.gwdg.de) \\ Accepted 2 April 2001 \\ Journal of Cell Science 114, 2437-2447 (C) The Company of Biologists Ltd
}

\section{SUMMARY}

Epidermal growth factor receptor (EGFR, erbB1) activation and translocation of the Shc adaptor protein to activated receptors were analyzed at the subcellular level by dual-label immunofluorescence and confocal laser scanning microscopy in conjunction with a new microsphere-based protocol. In the Quantitative Microsphere Recruitment Assay (QMRA) introduced here, epidermal growth factor-coated $1 \mu \mathrm{m}$ diameter microspheres were distributed over the surface of adherent tissue culture cells expressing the receptor. High-resolution confocal microscopy of a fusion construct of the receptor and the green fluorescent protein expressed in Chinese hamster ovary cells demonstrated that engulfment and internalization of the microspheres occurred rapidly within minutes, and in a receptor activation-dependent manner. In human epidermoid carcinoma A431 cells, receptor activation and She translocation persisted over the 20minute time course of the experiments. However, at the subcellular level the positive correlation of receptor activation and She translocation observed at 5-8 minutes dissipated, indicating a time-dependent decoupling of the two events and variation in the kinetics of signal transduction for different subcellular locations.

Key words: Tyrosine kinase inhibitor PD153035, Confocal laser scanning microscopy, Immunofluorescence, Digital image processing, QMRA

\section{INTRODUCTION}

Intracellular signal transduction takes place in the context of subcellular compartments, including the highly organized meshwork of the cytoskeleton. Scaffolding proteins also contribute to the organization of the signal transduction machinery (Newton, 1996; Whitmarsh and Davis, 1998; Colledge and Scott, 1999). Evidence is accumulating that this structural order is indispensable for the propagation and processing of signals. Fluorescence microscopy reveals that these elements are distributed heterogeneously throughout the cell with spatial variations on the micron scale. Standard biochemical techniques are unable to assess the impact of this organization on signaling specificity and kinetics. For this purpose, methods need to be devised that preserve the integrity of the cell and operate at the spatial resolution dictated by the dimensions of the subcellular structures. In this study $1 \mu \mathrm{m}$ microspheres were employed to quantitatively analyze the kinetics of signal transduction at the subcellular level. Central to our investigation was a concept of signaling coherence leading to the following questions. (1) Does signal transduction follow the same kinetics at different subcellular locations, thereby maintaining a constant distribution of activation states? (2) Is there a convergence to similar activation states? (3) Alternatively, do correlated activities dissipate? We addressed these issues by investigating the translocation of the adaptor protein Shc to the epidermal growth factor receptor (EGFR,
erbB1), locally activated with epidermal growth factor (EGF)coated microspheres.

The EGFR is prototypic for the family of receptor tyrosine kinases (RTK; Ullrich and Schlessinger, 1990), with proteinprotein interactions constituting the basis for the transduction of intracellular signals (Alroy and Yarden, 1997; Olayioye et al., 2000). The adaptor protein Shc (Pelicci et al., 1992) plays a central role in signaling via the EGFR, binding the activated receptor through its $\mathrm{N}$-terminal phosphotyrosine binding domain (PTB) and C-terminal SH2 domain (SH2) with subsequent phosphorylation of tyrosine residues in the central collagenhomology domain 1 (CH1; Gotoh et al., 1997). These serve in turn as recognition sites for additional downstream components, among them the adaptor protein Grb2 (Egan et al., 1993), finally leading to activation of p21ras and signaling through the cascade of mitogen-activated kinases (MAPK; Blumer and Johnson, 1994). Analyses of the distribution of Shc in unstimulated cells by confocal immunofluorescence microscopy and electron microscopy (Lotti et al., 1996) have revealed a perinuclear and reticular distribution, reflecting an association with the cytoplasmic side of the rough endoplasmic reticulum, the nature of which is unknown. Shc is therefore a candidate protein whose signaling potential may vary at the subcellular level. Since Shc binds to the activated EGFR directly but also participates in other signaling events, there is a conceptual basis for both correlation of translocation to the activation state of the EGFR and modulation of this activity by downstream activities. 
Microspheres with tightly coupled ligands constitute highly localized, non-diffusive stimuli for the cell surface receptor and have been employed in a number of cellular systems. For example, bFGF-coated microspheres led to clustering of acetylcholine-receptors in fibroblasts (Peng et al., 1991; Baker et al., 1992). Sequestration of receptor tyrosine kinases to sites of integrin signaling (Miyamoto et al., 1996) as well as longrange effects of integrin- and cadherin-coated microspheres on cellular phosphotyrosine levels (Levenberg et al., 1998) have also been demonstrated. Image analysis in these studies was mostly semi-quantitative, discriminating in a binary fashion between microspheres positive or negative for the given protein (Miyamoto et al., 1996). Levenberg and colleagues (Levenberg et al., 1998) introduced a quantitative form of image analysis, in which the investigator manually selects regions-of-interest in subregions of cells. In other studies, colocalization was quantitated by disruption of the beads from the cells and subsequent SDS-polyacrylamide gel electrophoresis (Plopper and Ingber, 1993; Miyamoto et al., 1995). As the beads were $5-12 \mu \mathrm{m}$ in diameter, it is conceivable that they may have led to a significant perturbation of the surface and internal structure of the cell. Such beads are also too large for correlating protein colocalizations with a spatial resolution adequate for assessing subcellular heterogeneity.

In the quantitative microsphere recruitment assay (QMRA) described and used in this report, a growth factor is covalently coupled to microspheres that are small (1 $\mu \mathrm{m}$ diameter) compared to the size of the cell. The cells are incubated with the beads for different durations of time. Activation of cell surface receptors and recruitment of downstream factors to the activated receptors are investigated by confocal immunofluorescence microscopy. A comprehensive quantitative analysis is achieved by image-processing protocols that filter the microsphereassociated signals from noise and background and automatically quantitate large numbers of objects. Since cellular integrity is fully preserved, a quantitative assessment of intracellular processes in the face of subcellular heterogeneity is possible. The specific and rapid internalization of ligand-coated microspheres within minutes, and the inhibition of these processes by receptorspecific tyrosine kinase inhibitors, indicate that such small microspheres elicit physiological responses that are normally observed with soluble ligands. The observation of some of these phenomena was greatly facilitated by employing cells expressing a fusion protein of EGFR with a Green Fluorescent Protein (GFP) (Brock et al., 1999a; Brock et al., 1999b).

\section{MATERIALS AND METHODS}

\section{Cell culture}

A431 human epidermoid carcinoma cells (Fabricant et al., 1977), Balb/c 3T3 cells, Chinese hamster ovary $(\mathrm{CHO})$ cells (obtained from Y. Yarden, Weizmann Institute, Rehovot, Israel) and transfected cell lines were grown in a $5 \% \mathrm{CO}_{2}$ humidified atmosphere at $37^{\circ} \mathrm{C}$ in DMEM supplemented with $10 \% \mathrm{FCS}, 10^{4}$ i.u./l penicillin $\mathrm{G}$ and 100 $\mathrm{mg} / \mathrm{l}$ streptomycin sulfate. For stimulation experiments, cells were starved for 24 hours in serum-free DMEM medium. Cells were propagated every 3-4 days.

\section{Generation of EGFR-GFP fusion proteins and transfected cell lines}

The EGFR-GFP fusion protein was generated as described elsewhere
(Brock et al., 1999a). The EGFR was derived from an EGFR cDNA (Ullrich et al., 1984) in pcDNA3 (Invitrogen, Carlsbad, CA, USA; obtained from Y. Yarden) and cloned into the pEGFP-N3 plasmid (Clontech, Heidelberg, Germany). CHO cells were seeded in $35 \mathrm{~mm}$ Petri dishes at a confluency of $10-15 \%$. The following day, the DMEM was replaced with $0.8 \mathrm{ml}$ Optimem (Gibco Life Technologies, Eggenstein, Germany), supplemented with antibiotics. $1 \mu \mathrm{g}$ of pEGFPN3 plasmid DNA and $3 \mu \mathrm{l}$ of a non-commercial transfection agent $(\mathrm{H}$. Eibl, Max Planck Institute for Biophysical Chemistry, Göttingen, Germany) or $6 \mu$ Lipofectin (Gibco) were incubated separately with $100 \mu \mathrm{l}$ of Optimem for 15 minutes, followed by another 30 minutes after mixing of the two solutions at room temperature. Transfection took place in a final volume of $1 \mathrm{ml}$ over 24 hours. Cells expressing the fusion construct (E-CHO) were selected in medium supplemented with $0.4 \mathrm{mg} / \mathrm{ml} \mathrm{G} 418$ (Gibco) and two rounds of cell sorting (Epics Elite, Coulter Electronics, Krefeld, Germany) at 2-week intervals. The structural and functional integrity of the EGFR-GFP fusion protein localized to the plasma membrane has been characterized in detail (Brock et al., 1999a; Brock et al., 1999b).

\section{Preparation of liganded microspheres}

Natural murine EGF was purchased from IC Chemikalien (Ismaning, Germany). Carboxy-functionalized super-paramagnetic $1 \mu \mathrm{m}$ beads (SERA-MAG, Seradyn, Indianapolis, USA) were activated with 0.1 M sulfo-NHS (N-hydroxysulfosuccinimide; Pierce, Rockford, USA), 0.1 M EDC (1, ethyl(-3-[3-dimethylaminopropyl]carbodiimide hydrochloride; Pierce) in 0.1 M MES (Sigma, Deisenhofen, Germany) buffer, $\mathrm{pH} \mathrm{5,} \mathrm{for} 1$ hour at room temperature. After washing twice in $0.1 \mathrm{M}$ MES, the microspheres were equilibrated in coupling buffer ( $0.1 \mathrm{M}$ sodium phosphate, $\mathrm{pH}$ 8). The coupling reaction was carried out at $4{ }^{\circ} \mathrm{C}$ overnight with $50 \mu \mathrm{g}$ EGF in $30 \mu \mathrm{l}$ coupling buffer per 6 $\mu \mathrm{l}$ of the $5 \%$ bead slurry with constant agitation. Beads used as negative controls in immunofluorescence experiments were incubated with ethanolamine or BSA (Sigma). Finally, the beads were washed twice with coupling buffer and then thoroughly with PBS after quenching remaining activated groups with $1 \mathrm{M}$ ethanolamine for 2 hours at room temperature. The microspheres were stored in PBS with $0.1 \%$ sodium azide. The presence of intact EGF on the surface of the microspheres was demonstrated in a bead agglutination assay (Dezelic et al., 1971) with an anti-murine EGF rabbit polyclonal antibody (Sigma). A nonspecific antibody was inactive.

\section{Preparation of fluorescently labeled antibodies}

Mouse monoclonal antibody against the activated isoform of the human EGFR (anti-EGFRa) and rabbit polyclonal anti-Shc antibody were purchased from Transduction Laboratories (Lexington, KY, USA). BSA present in the antibody preparations was removed prior to fluorescent labeling with pre-packed $1 \mathrm{ml}$ protein-G columns (AGS, Heidelberg, Germany). The antibodies were concentrated to $100 \mu \mathrm{g} / \mathrm{ml}$ in Microcon 100 microconcentrators (Amicon, Witten, Germany) and labeled with a tenfold molar excess of the NHS-esters of the indocyanine dyes Cy3 and Cy5 (Amersham Buchler, Braunschweig, Germany; Southwick et al., 1990) for 30 minutes at room temperature in $100 \mathrm{mM}$ sodium bicine, $\mathrm{pH} 8$ (Sigma). The reaction was quenched with $5 \mu \mathrm{l} 1 \mathrm{M}$ glycine. Unreacted dye was removed on an Econo-Pac 10DG column (BioRad, Richmond, CA, USA). The antibody fraction was concentrated in Microcon 100 microconcentrators and the molar labeling ratios (dye:antibody) were determined with UV spectroscopy according to the specifications of the supplier. They were in the ranges of 1-3 for different preparations. The antibodies were stored in $50 \%$ glycerol, $0.1 \%$ BSA, $0.1 \%$ sodium azide at $-20^{\circ} \mathrm{C}$. A single preparation of each of the antibodies was used for all of the experiments.

\section{Microsphere experiments and immunofluorescence microscopy}

Cells were seeded on $12 \mathrm{~mm}$ diameter glass coverslips. For measurements of receptor activation after 2 days of culture the cells were 

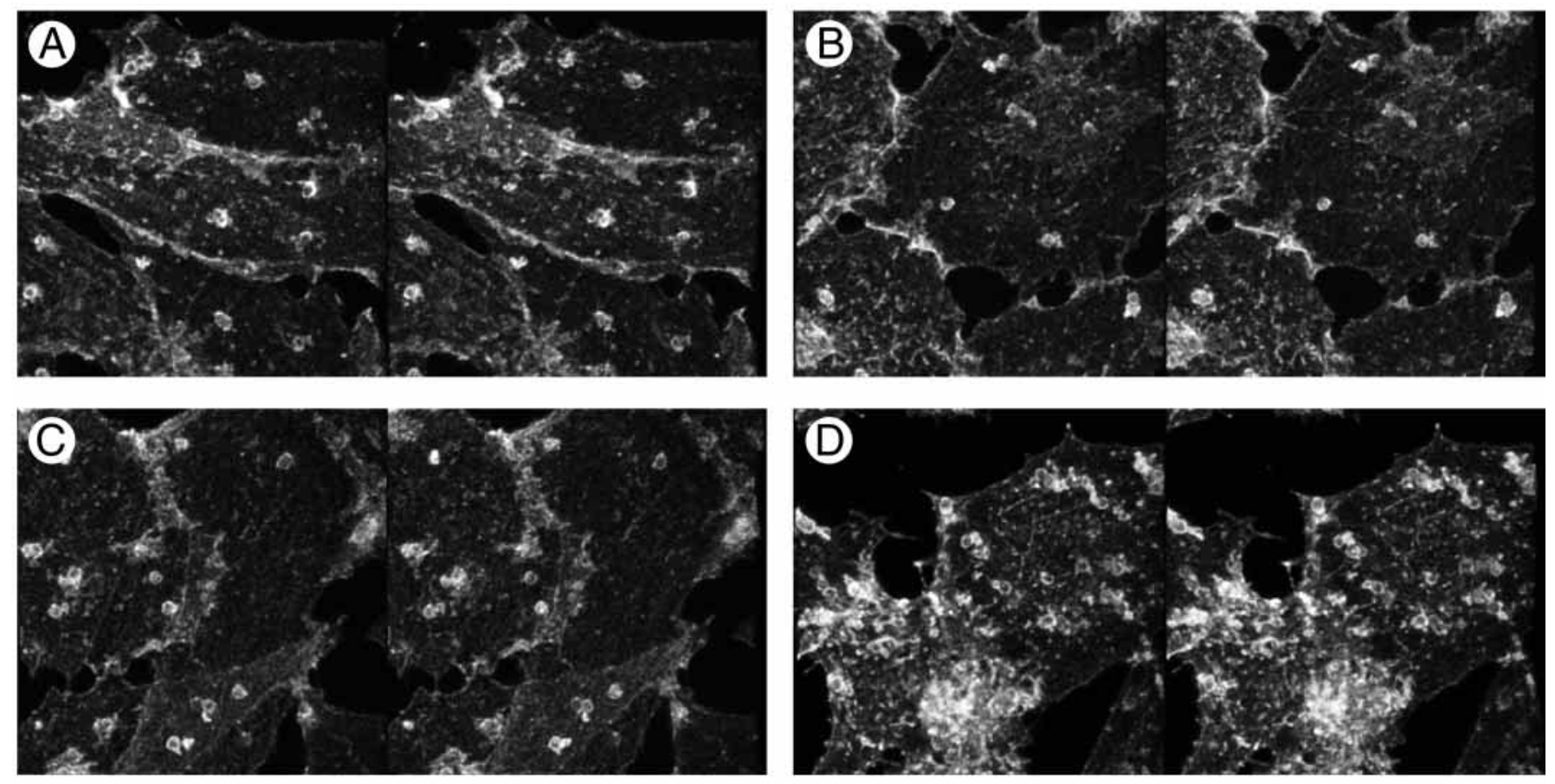

$10 \mu \mathrm{m}$

Fig. 1. Internalization of EGF-coated microspheres. Shown are stereo-images of GFP fluorescence of E-CHO cells (expressing the EGFR-GFP fusion protein) after 2 minutes (A), 5 minutes (B), 8 minutes (C) and 20 minutes (D) incubation with the microspheres. By 2 minutes most microspheres were completely engulfed by the plasma membrane. At 8 minutes, the distribution of fluorescence around the microspheres appeared less fuzzy. At 20 minutes some microspheres had translocated to the basal side of the cell. The stereo-images were processed in such a way that the cell-coverslip contact is oriented towards the observer. The microspheres themselves were not fluorescent, but could be visualized in the confocal reflection mode. The fluorescence stacks were deconvoluted as described in Materials and Methods.

serum starved for 24 hours and used at a confluency of $70-90 \%$. The cells were washed twice in HBS (Hepes-buffered saline: $135 \mathrm{mM} \mathrm{NaCl}$, $10 \mathrm{mM} \mathrm{KCl}, 0.4 \mathrm{mM} \mathrm{MgCl} 2,1.0 \mathrm{mM} \mathrm{CaCl} 2,5.6 \mathrm{mM}$ glucose, $0.1 \%$ BSA, $10 \mathrm{mM}$ Hepes (Sigma), $\mathrm{pH}$ 7.4) and warmed to $37^{\circ} \mathrm{C}$ in a humid incubation chamber with $50 \mu \mathrm{l} \mathrm{HBS}$ for 5 minutes. To accelerate the sedimentation of the magnetic microspheres, magnets were placed underneath the coverslips in the humid incubation chambers. Microspheres were added in another $50 \mu \mathrm{l}$ at a density of 1-10 per cell and the incubation was carried out over the indicated times. The cells were rinsed in ice-cold HBS and fixed in $3.7 \%$ paraformaldehyde for 5 minutes on ice, followed by 10 minutes at room temperature. The coverslips were washed three times with PBS, and once with $100 \mathrm{mM}$ Tris-HCl, $\mathrm{pH} 7.4,50 \mathrm{mM} \mathrm{NaCl}$. The cells were permeabilized with $0.1 \%$ Triton X-100 (Fluka Sigma-Aldrich Chemie, Deisenhofen, Germany) in PBS for 10 minutes at room temperature, followed by three more washes with PBS. Incubations with fluorescently labeled primary antibodies were carried out at concentrations of approx. $1 \mu \mathrm{g} / \mathrm{ml}$ in $50 \mu \mathrm{l} \mathrm{PBS} / 0.2 \%$ BSA for 1 hour at room temperature. The EGFR was probed with an anti-EGFR mouse monoclonal antibody (clone F4, Biomol Feinchemikalien, Hamburg, Germany) in combination with a Cy3labeled goat anti-mouse secondary antibody (Jackson ImmunoResearch Laboratories, West Grove, PA, USA). Cells were washed four times with PBS for 15 minutes and mounted on microscope slides in $0.1 \mathrm{M}$ Tris$\mathrm{HCl}, \mathrm{pH} 8.5,25 \%$ (w/v) glycerol, and 10\% Mowiol 4-88 (Hoechst Pharmaceuticals, Frankfurt, Germany; Osborn and Weber, 1982). For high-resolution confocal analyses of the cellular morphology about the microspheres, E-CHO cells incubated with microspheres were fixed by incubation with PFA for 5 minutes at $4^{\circ} \mathrm{C}$ and 10 minutes at room temperature, followed by three 5 minute washes with $\mathrm{HBS}$ and a subsequent methanol fixation for 6 minutes at $-20^{\circ} \mathrm{C}$.

The EGFR-specific tyrosine kinase inhibitor PD153035
(Calbiochem-Novabiochem, Bad Soden, Germany; Fry et al., 1994) was used at a concentration of $1 \mu \mathrm{M}$. Before addition of microspheres, cells were incubated in HBS supplemented with inhibitor, followed by PFA fixation in the presence of the inhibitor. A $5 \mathrm{mM}$ DMF stock solution was stored at $-20^{\circ} \mathrm{C}$. Control microsphere experiments with DMF diluted 1:5000 were included.

Confocal laser scanning fluorescence microscopy was carried out with an LSM310 system (Carl Zeiss, Göttingen, Germany) and a 63×, 1.4 NA Plan-Apochromat oil immersion objective. GFP was excited at $488 \mathrm{~nm}$ with the internal Argon-ion laser and its emission selected through a 530DF30 bandpass filter (Omega Optical). For signaling experiments with A431 cells, Cy3 was excited with a $1 \mathrm{~mW} 543 \mathrm{~nm}$ $\mathrm{He}-\mathrm{Ne}$ laser (PMS Electro-Optics, Boulder, CO, USA) and its emission selected through a 590DF35 bandpass filter (Omega Optics, Brattleborough, USA). Cy5 was excited with a tenfold attenuated 5 $\mathrm{mW} 633 \mathrm{~nm}$ He-Ne laser and detected through a LP665 long-pass filter (Carl Zeiss). The lateral and axial sampling frequencies varied between experiments and are given in the Results section. In most cases images were recorded with two- to fourfold oversampling in the $x$ and $y$ dimensions and oversampling to various degrees in the $z$ dimension. The sampling time per frame was 2 seconds, with twofold frame-averaging for a stack of 20 slices and fourfold averaging for 10 slices. In all cases, reflection images were acquired in parallel with the fluorescence stacks for the identification of the microspheres, using the 100-fold attenuated $633 \mathrm{~nm}$ laser.

\section{Image analysis}

Image processing was carried out with SCIL-IMAGE (University of Amsterdam, TNO Institute of Applied Physics, Delft, The Netherlands). Before segmentation, deconvolutions employing Maximum a posteriori approaches based on Good's roughness (MAPPR; Verveer and Jovin, 
Fig. 2. Disposition of the plasma membrane about the microspheres after 2 minutes (A) and 8 minutes (B) incubation of E-CHO cells with EGF-coated microspheres. Each panel presents one confocal slice of the total image (left) and two sets of enlargements of the microspheres located in the regions-of-interest defined in the overviews. One $x y$ slice out of a total of 20 , and $x z-$ and $y z$-projections along the indicated lines are shown. Outlines of the morphology of the plasma membrane as derived from the fluorescence images are included. (A) Microspheres, located in an invagination of the plasma membrane reaching down nearly the entire thickness of the cell. In other cases, engulfment was complete at 2 minutes. (B) Microsphere internalized into the cell, concluded from the presence of fluorescence of the outer membrane above the microsphere. Deconvolution was carried out as described in Materials and Methods.
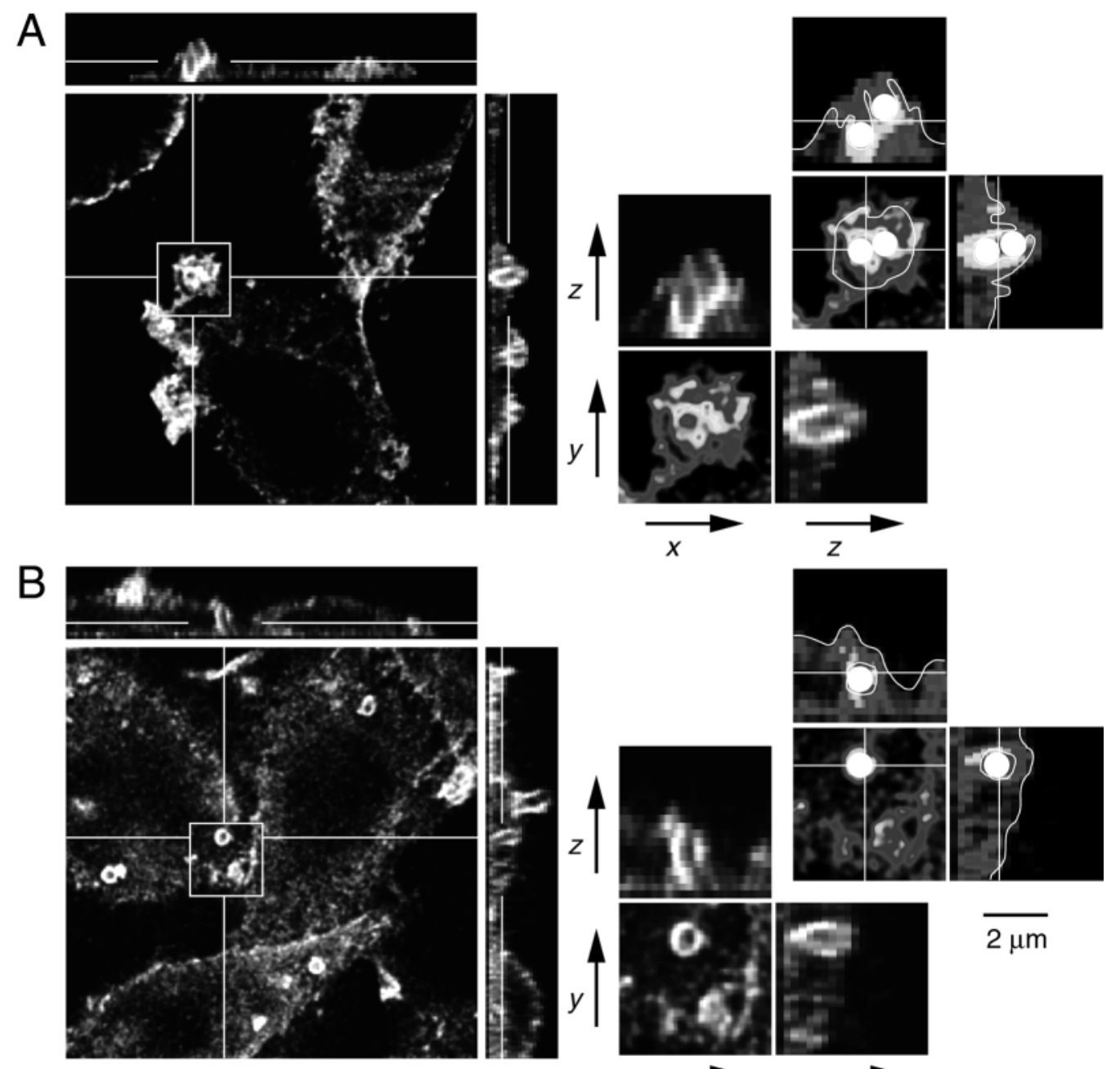

$10 \mu \mathrm{m}$
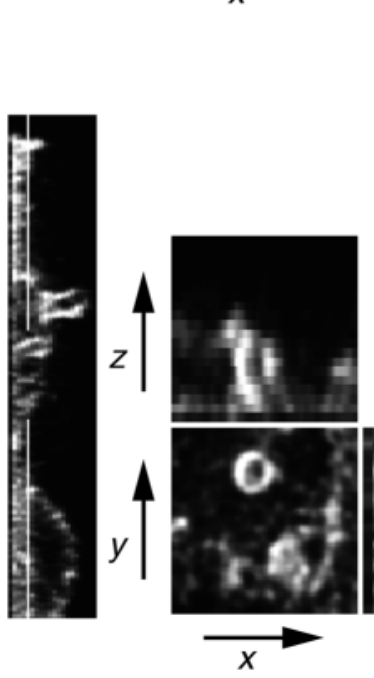
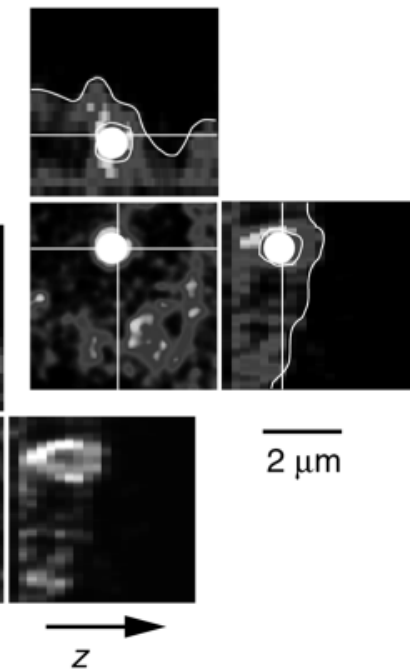

$2 \mu \mathrm{m}$
1998) and calculated point-spread-functions (PSF; van de Voort and Brakenhoff, 1990) were carried out. The special functions for the quantitative analysis of bead-associated fluorescence were written in $\mathrm{C}$ and implemented in the SCIL-IMAGE package. The image analysis protocol performed a segmentation of the three-dimensional image stacks into bead-associated fluorescence, regions of fluorescence in the rest of the cell, and fluorescence in the local environment of the microspheres (in the case of Shc translocation). The local environment was selected as a region of closest vicinity to the microsphere that was deemed unaffected by changes in membrane morphology or protein recruitment. The image processing procedure is illustrated in Fig. 5 and a detailed description will be given elsewhere.

\section{RESULTS}

Heterogeneity in signal transduction at the subcellular level was addressed by quantitative analysis of receptor activation and activation-dependent translocation of the adaptor protein Shc using EGF-coated microspheres. The human epidermoid carcinoma cell line A431 was chosen for these experiments since it very likely represents the best-studied model system for EGFR signaling, allowing comparison of our data with a large body of published results on receptor function and kinetics of downstream signal transduction. Microsphere internalization and the membrane disposition about the microspheres were addressed with a newly established CHO-derived cell line (E$\mathrm{CHO}$ ) expressing a fusion protein of the EGFR with GFP at the C terminus (EGFR-GFP(C); Brock et al., 1999a). After fixation, A431 cells were too flat for these features to be distinctly resolved with high-resolution confocal microscopy. In addition, the E-CHO cells represented an independent control for receptor recruitment and the image processing procedure.

\section{Microsphere engulfment and internalization}

The potential of the EGF-coated microspheres to internalize was a major concern with respect to downstream molecular events occurring after EGFR endocytosis (Vieira et al., 1996). Chemical modification via the N-terminal amino-group of murine EGF does not impair receptor binding or activation, as was demonstrated for fluorescently labeled EGF (Gadella and Jovin, 1995) or EGF coupled to solid supports (Ito et al., 1998). E-CHO cells were incubated with the EGF-coated microspheres for 2, 5, 8 and 20 minutes and analyzed with confocal microscopy followed by image deconvolution for axial resolution enhancement (Figs 1, 2) (Verveer and Jovin, 1998). After 2 minutes, most microspheres were already fully engulfed by the plasma membrane (Figs 1A, 2A). At 8 minutes internalization was complete (Figs 1C, 2B) and translocation 
towards the basal side of the cells was evident (Fig. 1D). To determine whether microsphere internalization required the activation of the receptors, E-CHO cells were incubated with microspheres in the presence of the EGFR-specific tyrosine kinase inhibitor PD153035 (Fry et al., 1994). In contrast to all other experiments, the engulfment of the beads was only partial (Fig. 3). In some cases, only receptor recruitment to the site of microsphere contact was apparent. The inhibitor was diluted 1:5000 from a DMF stock-solution. However, DMF alone had no effect on the engulfment process described above. Although not quantitated in detail, fewer microspheres were present in inhibitor-treated cells than in control samples.

\section{Microsphere-induced signal transduction}

On A431 cells as well, sequestration and activation of EGFR were specific for EGFcoated microspheres (Fig. 4A,B), monitored by monoclonal antibodies specific for the EGFR and the activated isoform of the receptor. The receptor activation remained confined to the sites of microsphere attachment. Ethanolamine- and BSAcoated microspheres were inactive. To verify that the localized fluorescence signal was not due to nonspecific aggregation of antibody within the microsphere-cell contact site, a fluorescent secondary antibody was used on A431 cells alone and fluorescently labeled anti-EGFRa was used on murine Balb/c 3T3 cells, which carry a low number of EGFR. No fluorescence was observed in these cases. Confocal immunofluorescence microscopy on cells that had been incubated for 5 minutes with EGF-coated microspheres demonstrated a clear translocation of Shc to the microspheres (Fig. 4C).

The results of the image segmentation processes for extracting quantitative information are summarized for three subcellular sites in Fig. 5. In the case of EGFR activation little fluorescence was present at locations away from the microspheres. Image processing isolated the bead-associated fluorescence. The image processing protocol for Shc translocation extracted the bead-associated fluorescence as well as image information in the local environment. It is important to note that analysis of activation-dependent Shc translocation is partially perturbed by the heterogeneity of Shc concentration at the subcellular level. In the absence of Shc translocation, Shc fluorescence at the microsphere would be identical to that in the local environment. Recruitment of Shc to activated receptors is expected to occur, at least initially, from the local Shc pool without a perceptible increase in the Shc signal, but later this may well operate over larger distances. For this reason, at high local Shc concentrations and low levels of receptor activation, the local Shc signal may not increase in a manner reflecting receptor activation, whereas at low local Shc signals the signal at the microspheres should correlate more strongly with receptor activation. Thus, we performed the analysis of activation-dependent Shc translocation by subdividing the data into subsets of low, medium and high local Shc concentrations. The accuracy of the image segmentation procedure was determined by correlating microsphereassociated EGFR-GFP fluorescence with the signal in the local environment on E-CHO cells. The correlation coefficients were approximately 0.95 , demonstrating that the experimental
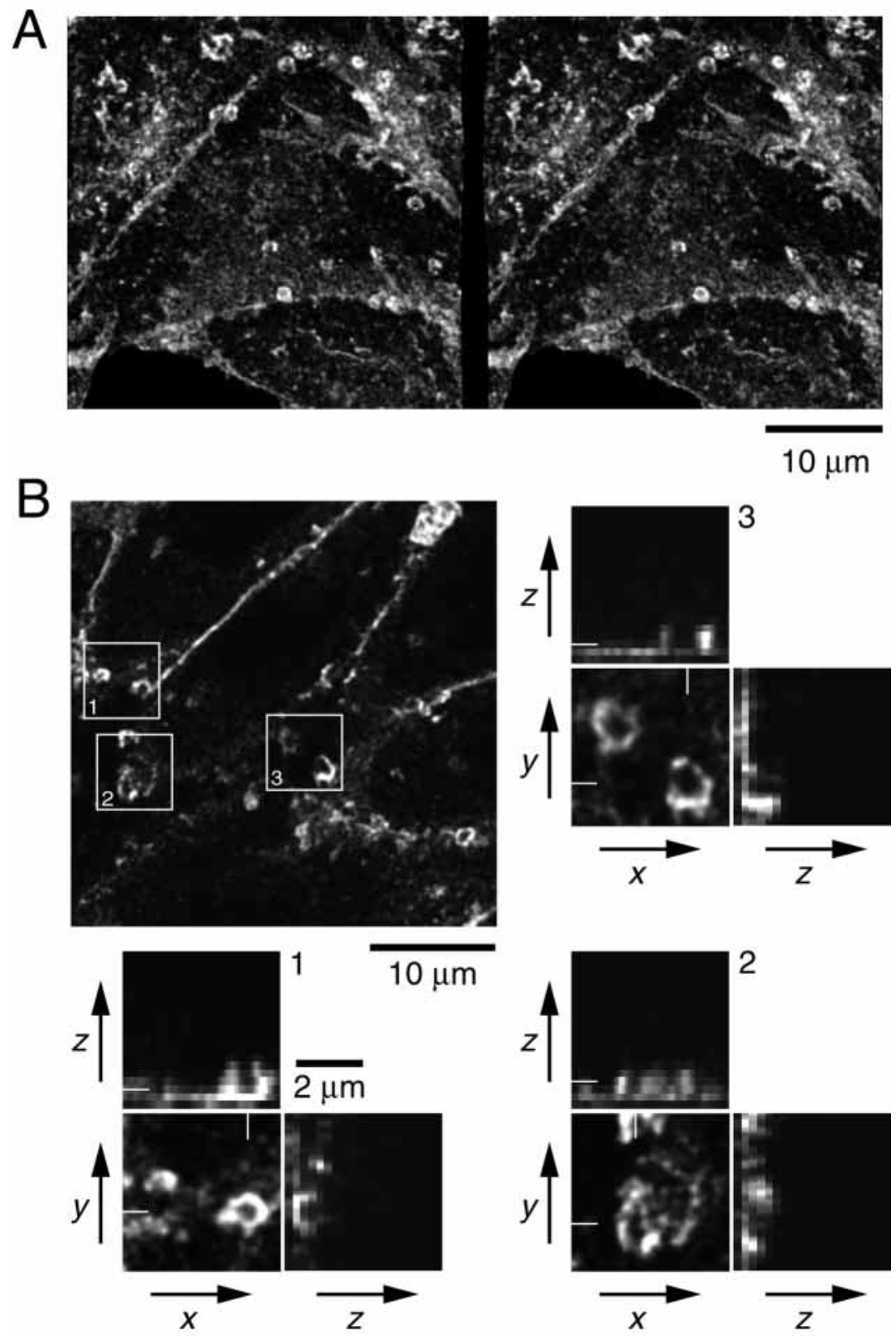

Fig. 3. Inhibition of internalization of EGF-coated microspheres in the presence of the EGFR-specific tyrosine kinase inhibitor PD153035. (A) Stereo-images of GFP fluorescence of E-CHO cells 5 minutes after contact with EGF-coated microspheres. In contrast to Fig. 1, the apical face of the cells is oriented towards the observer. (B) Examples of plasma membrane morphology of E-CHO cells in contact with EGF-coated microspheres after 5 minutes incubation with the microspheres. The locations of the enlarged regions of interest 1-3 are boxed in the overview, showing one confocal slice. A set of three orthogonal sections is given in each case; the positions of the sections are indicated. The sampling frequency along the optical axis was $0.3 \mu \mathrm{m}$. The fluorescence stacks were deconvoluted as described in Materials and Methods. 


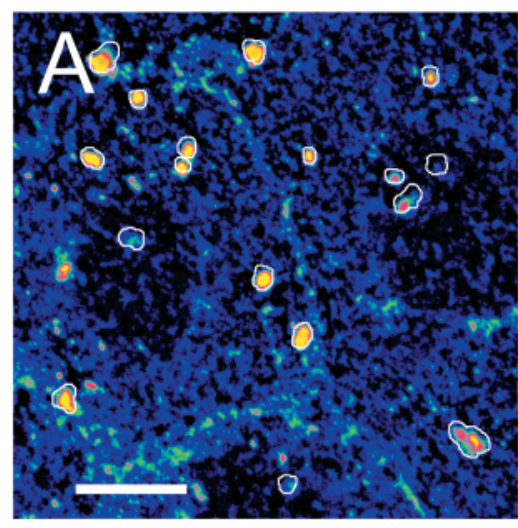

anti-EGFR

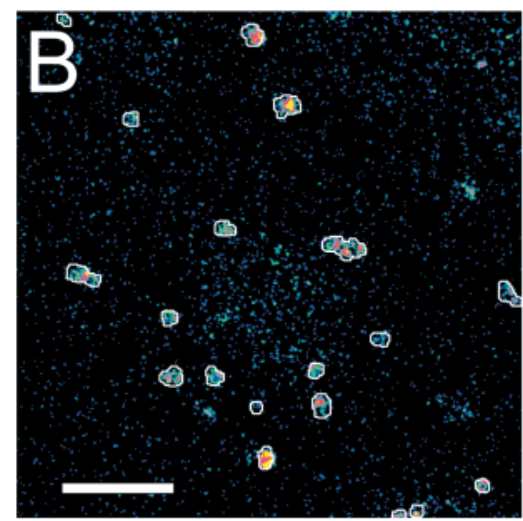

anti-EGFR (activated)

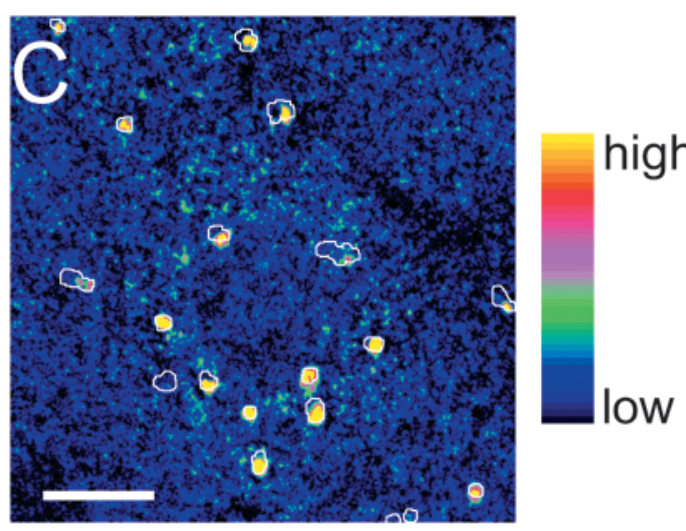

anti-Shc

\section{double staining}

Fig. 4. Immunofluorescence microscopy with EGF-coated microspheres. (A) Sequestration of the EGF receptor. The dynamic range of the look-up-table was adjusted according to the fluorescence intensities in the cells. Thus, the bead-associated fluorescence appears to be saturated. (B,C) Double labeling of cells to probe for activation of the EGF receptor (B) by a monoclonal antibody specific for the activated isoform of the EGF receptor and (C) translocation of Shc to the activated EGF receptor. One slice out of a stack of eight is shown in each case, accounting for the different intensities of the signals at microspheres located in different focal planes. As in A, the dynamic range of the look-up-table was adjusted to display the fluorescence in the cells. Bar, $10 \mu \mathrm{m}$. The locations of the microspheres detected by confocal reflection are superimposed by white outlines.

procedures and image processing contributed little to the overall noise.

\section{Time-dependence of signal transduction at the EGF- coated microspheres}

The time course of receptor activation and Shc recruitment at the subcellular level was analyzed in more detail. Figs 6 and 7 summarize the data from three independent experiments, each scaled to compensate for quantitative differences due to instrument factors (laser intensity, pinhole adjustment) based on calibration samples.

Frequency histograms for EGFR activation as well as for Shc translocation revealed a time-dependent shift and broadening of the distributions (Fig. 6). The mean Shc signal increased by $75 \%$ from 2 to 8 minutes; no further increase was observed for the 20 minute time point. The 20 minute points demonstrated an additional increase in the fractions of microspheres for the low as well as the very high Shc signals.

Control experiments analyzing the density of EGFR at the microspheres indicated that the kinetics of receptor activation and Shc translocation were unaffected by ongoing EGFR recruitment to the microspheres. Neither for A431 nor for E-CHO cells was a change of receptor density observed (not shown). Consistent with a qualitative assessment of the image data (Figs 1,2) the receptors were already enriched at the microspheres after 2 minutes. No discernible depletion of receptors in the surrounding region was observed in either case, from which we conclude either that this effect was negligible or that long-range reequilibration of receptors occurred very rapidly.

\section{Correlation of EGF receptor activation, Shc translocation and the local Shc concentration at the subcellular level}

For each microsphere a data set that included EGFR activation, local Shc concentration and Shc signal at the microspheres was extracted from the confocal images by the image processing protocol.

At 2 minutes the data points for EGFR activation clustered, without a perceivable correlation between EGFR activation and Shc translocation. However, a positive correlation was apparent at 5 and 8 minutes. By 20 minutes the positive correlation had vanished and the distribution of the data points widened. The values for receptor activation did not extend below a certain value, dictated by thresholding in the image processing procedure. Consistent with the assumption outlined above, high levels of local Shc concentration disguised the positive correlation of Shc translocation and receptor activation. To further compensate for the perturbation of the correlations by the local Shc concentration, the data within one data set were slightly smoothed by local averaging.

The scatter plots in Fig. 7 showed an increase of EGFR activation and Shc translocation with time as well as a buildup and an ultimate dissipation of a positive correlation between both parameters. In addition to shifting towards higher or lower values, the distributions of the 20 minute data broadened for all combinations of high and low receptor activation levels and She translocation. The subcellular build-up and dissipation of the correlation of Shc translocation with EGFR activation were characterized quantitatively by calculating the linear correlation coefficients between both values (Table 1). The qualitative results evident in the scatter plots were confirmed quantitatively. The correlation coefficients reached a maximum of 0.8 at 5-8 minutes and decreased to below the 2 minute value at 20 minutes. As expected, the correlation coefficients for the subpopulation with low local Shc concentrations were higher than for the other subpopulations.

The change in the width of the distributions was quantitated by statistical methods employed in fluorescence-activated cell 

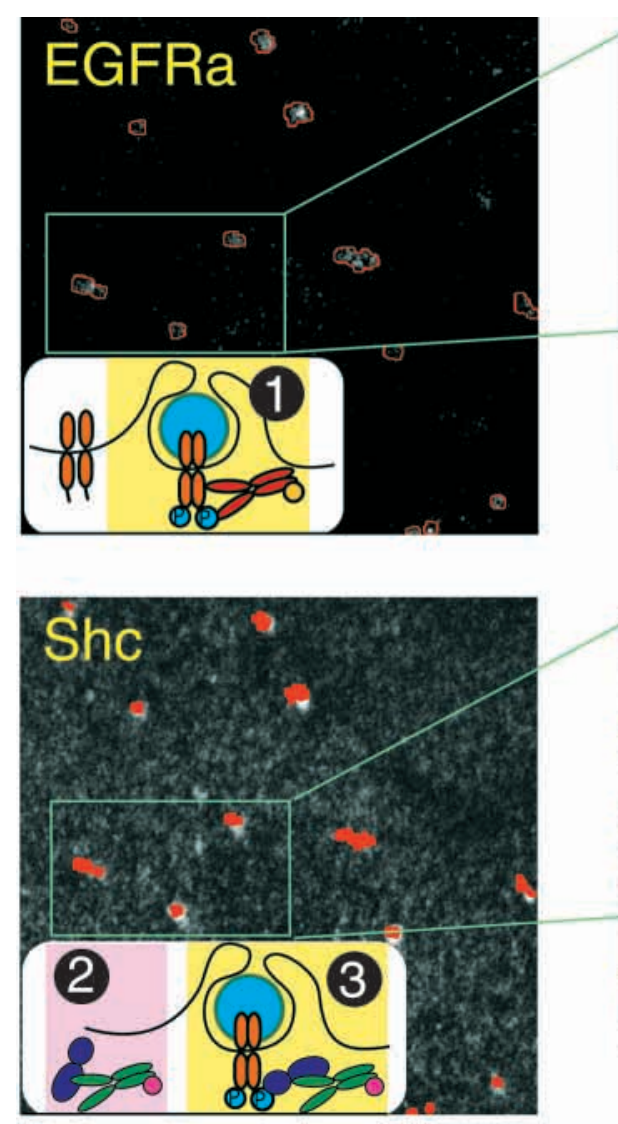
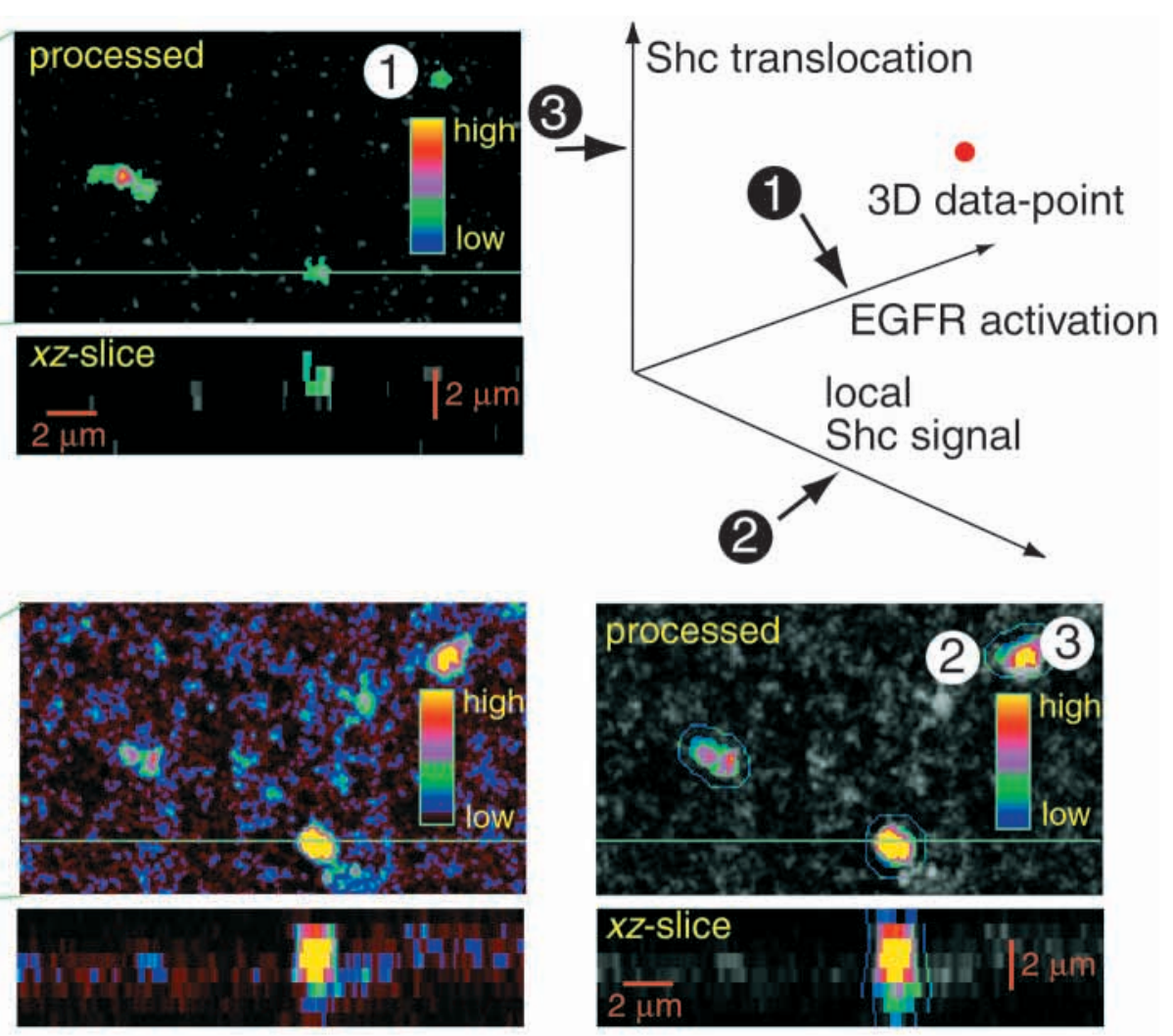

Fig. 5. Image processing protocols for isolation of the signals for EGFR activation and Shc translocation and generation of three-dimensional data sets. Schematics illustrating the immunofluorescence staining are included in the leftmost panels. The image processing protocol for the analysis of receptor activation only retains the signals colocalizing with the microspheres (colored pixels in the top center panel). The positions of the microspheres are outlined in red on one slice of the three-dimensional stack of confocal images. For She the signal at the microspheres as well as the Shc signal in the local environment are retained. The microspheres are again designated by red pixels. To illustrate the heterogeneous subcellular distribution of Shc more clearly an unsegmented enlargement is included in the bottom center panel. The colored ring around the microsphere-associated signal represents the local environment. An $x z$-projection through the image stacks is included for the enlarged areas. The final three-dimensional data set consists of (1) the level of EGFR activation, (2) the Shc signal in the local environment of a microsphere, and (3) the Shc signal colocalizing with the microsphere. The pseudocolor look-up table was chosen to better illustrate which data were isolated by the image processing procedure.

Table 1. Correlation coefficients for EGFR activationdependent Shc translocation

\begin{tabular}{cccc}
\hline & \multicolumn{3}{c}{$[$ Shc] } \\
\cline { 2 - 4 } Time (minutes) & Low & Medium & High \\
\hline 2 & $0.46 \pm 0.42$ & $0.44 \pm 0.17$ & $0.33 \pm 0.23$ \\
5 & $0.76 \pm 0.33$ & $0.56 \pm 0.39$ & $0.28 \pm 0.39$ \\
8 & $0.82 \pm 0.11$ & $0.66 \pm 0.17$ & $0.52 \pm 0.32$ \\
20 & $0.42 \pm 0.27$ & $0.42 \pm 0.28$ & 0.17
\end{tabular}

The data sets are subdivided into subsets of low, medium and high Shc concentration in the local environment.

Values are means \pm s.d. $(n=3)$.

Negative correlation coefficients were omitted from the calculation of the means. For this reason, no s.d. could be computed for the 'high' subset at 20 minutes.

sorting (FACS). The coefficients of variation (CV), where $\mathrm{CV}=$ s.d./mean, were calculated. Analysis of the CVs yielded important insights into the underlying subcellular signaling kinetics. Assuming linear activation kinetics common to all subcellular locations, the $\mathrm{CV}$ should remain constant. A decrease of the CV would imply a narrowing of the distributions, indicating a convergence towards identical activation levels, whereas an increase would imply a loss of signaling coherence at the subcellular level. If all receptors were equally activated for all microspheres after 20 minutes, a narrowing of the distributions of receptor activation would be expected. The concept of signaling coherence is proposed to qualitatively discriminate signaling events in which signal transduction propagates coherently with similar kinetics at all subcellular locations, from those characterized by a convergent or divergent temporal evolution. The $\mathrm{CV}$ for receptor activation doubled from 2 to 5 minutes, while the $\mathrm{CV}$ for Shc translocation increased by about $25 \%$. In control measurements of receptor recruitment to EGFRcoated microspheres, the CVs were the same for all time points.

\section{DISCUSSION}

\section{Microsphere-induced receptor internalization}

Internalization of EGF-coated microspheres on E-CHO cells occurred rapidly within minutes in a receptor 

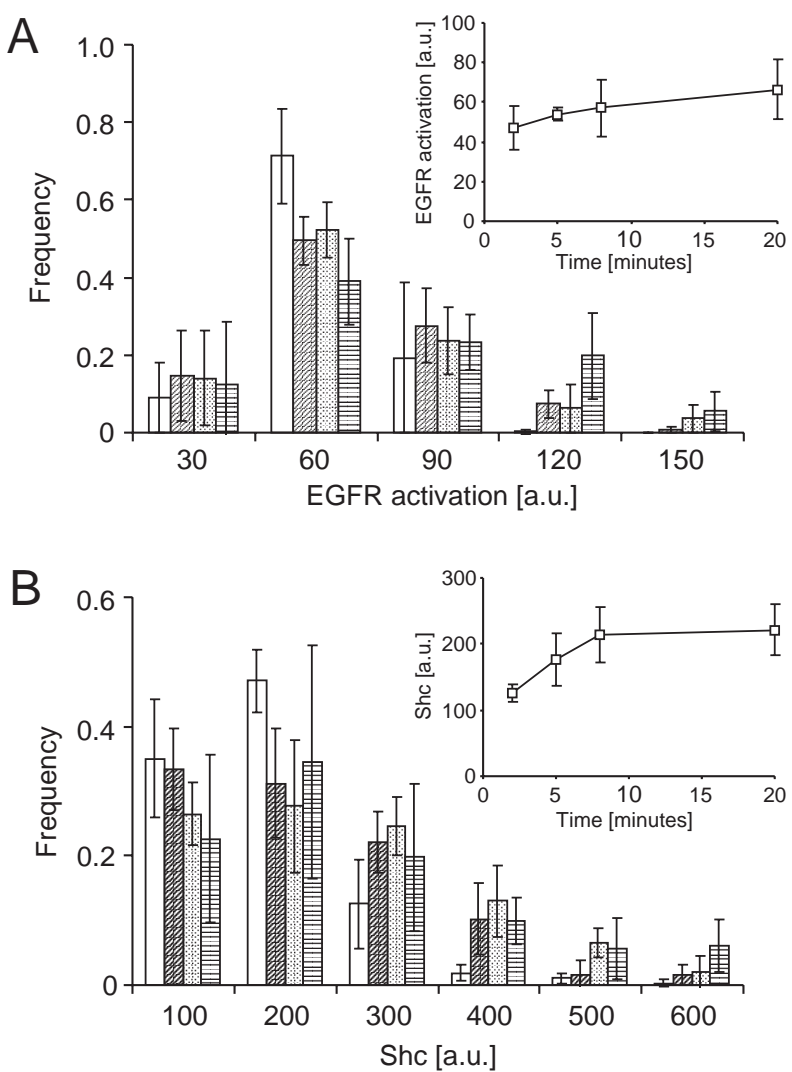

Fig. 6. Time dependence of (A) EGFR activation and (B) Shc translocation. Frequency histograms after 2, 5, 8 and 20 minute incubations of A431 cells with EGF-coated microspheres. Insets show mean receptor activation as well as Shc translocation expressed in arbitrary fluorescence units (a.u.). Values are means \pm 1 s.d. of three independent experiments.

activation-dependent way. Phagocytosis, receptor-mediated internalization and a zipper-like mechanism could account for the internalization of the EGF-coated microspheres. Of the three, phagocytosis seems the least likely, inasmuch as internalization by fibroblasts and COS cells competent for phagocytosis takes hours and is incomplete (Schroeder and Kinden, 1983; Lowry et al., 1998). In our experiments cells did not respond to EGF microspheres at all, while all EGFmicrospheres were internalized.

In the presence of the EGFR-specific tyrosine kinase inhibitor PD153035 the microspheres were only partially engulfed by the plasma membrane and no internalization occurred. Furthermore, the number of microspheres remaining on the cells after fixation and washing was lower than in untreated control samples.

We conclude that the $1 \mu \mathrm{m}$ EGF-coated microspheres elicited a cellular response similar to that observed for soluble EGF, thus constituting a valid approach for studying internalization-dependent signaling mechanisms. It will be interesting to investigate in more detail the degree to which the endocytic machinery adapts to morphological structures that are much larger than a regular endocytic vesicle.

\section{Time dependence of EGFR-dependent signal transduction in QMRA}

The image processing protocol readily isolated the beadassociated fluorescence and the fluorescence in the local environment. The constancy of the mean values and CVs for EGFR-based fluorescence detected in A431 cells by immunofluorescence and in E-CHO cells by intrinsic GFP fluorescence provided a twofold quantitative validation of the image processing procedure, and of the microsphere-based approach for following the temporal course of activation and activation-dependent Shc recruitment.

At 2 minutes, considerable receptor activation was already present. Due to the experimental protocol, a zero time point could not be included. QMRA requires binding of the microspheres to the cells; receptor activation and Shc translocation are thus unavoidable. As receptor activation would also occur if cells were cooled to $4^{\circ} \mathrm{C}$ (Nesterov et al., 1990), it was impossible to define the starting point by a rapid
Fig. 7. Time-dependent correlation of Shc translocation with the activation of EGFR. The data sets from three different experiments were subdivided for low, medium and high levels of Shc in the local environment. The intervals for the subsets were adjusted to roughly equal numbers of events per subset and were the same for all experiments. Values within each subset were smoothed by a moving average with a window size of five to further compensate for the effect of the local Shc concentration on the analysis of receptor-dependent Shc translocation. The arrow indicates those data points lying outside the major population that were caused by a high Shc concentration in the local environment. The values for EGFR activation do not extend below 20 a.u. because of thresholding in the image processing procedure.

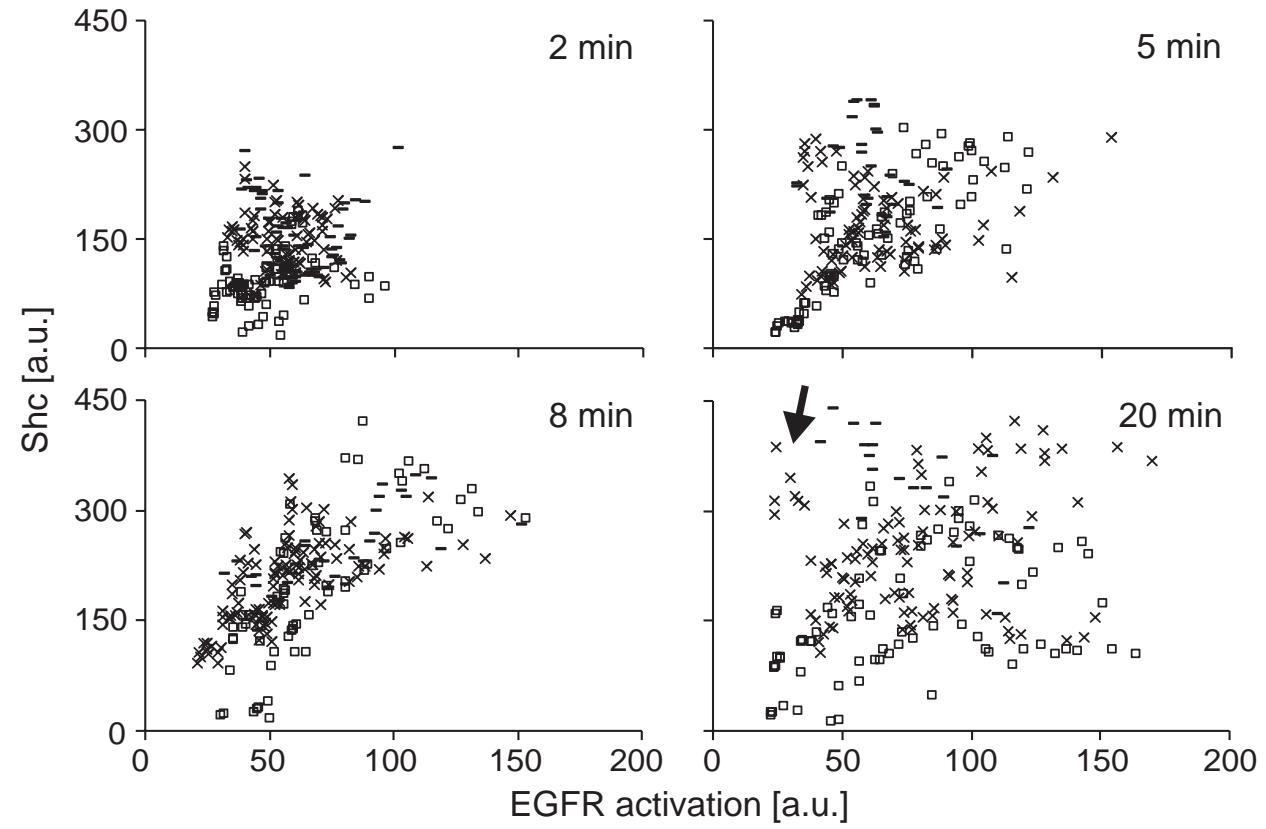


temperature shift to $37^{\circ} \mathrm{C}$. While one may argue that the very early molecular events are not accessible by QMRA, the molecular events of interest here, the build-up and dissipation of the correlations of EGFR activation and She translocation at the subcellular level, occurred between 2 and 20 minutes.

Receptor activation as well as Shc translocation persisted over the whole time course of the experiments. Compared to the 2 minute time point, mean receptor activation increased by a further $40 \%$, in agreement with the relative $40 \%$ increase from 1 to 20 minutes reported previously using the same activation-specific antibody (Emlet et al., 1997). Prior reports based on EGF coupled to solid supports provided only a qualitative demonstration of EGFR activation (Ito et al., 1998). The mean Shc translocation increased by $75 \%$ from 2 to 8 minutes; no further increase was observed for the 20 minute time point. The increase in both the fractions of microspheres with the lowest and the highest signals is indicative of a heterogeneous pattern of deactivation and activation pathways proceeding in parallel by the latest time point.

\section{Heterogeneous kinetics of EGFR-dependent signal transduction at the subcellular level}

The microsphere-based subcellular analysis revealed a new level of signaling complexity at the subcellular level. The increase of EGFR activation and Shc translocation at the global level present in the frequency histograms was in contrast to a build-up and dissipation of a correlation for She translocation with EGFR activation at the subcellular level (Table 1) and by the widening of the distributions for both values (Table 2).

In discussing the molecular basis of this observation, one should note the broad range of EGFR activation levels present at later time points. The surface density of receptors at the microspheres was higher than in the local environment and the number of receptors per microsphere did not depend on the subcellular environment (not shown). This recruitment should level out differences in subcellular receptor density and one might expect comparable activation levels for all microspheres. The variance in activation in spite of the constant receptor numbers could be explained by the presence of two subclasses of EGFR on A431 cells with high and low affinities for EGF (Gregoriou and Rees, 1984). Signal transduction has been shown to be mediated through the subclass of high affinity receptors (Defize et al., 1989), identified as the immobile fraction of EGFR bound to the cytoskeleton (Wiegant et al., 1986; Gronowski and Bertics, 1993). Therefore, recruitment should occur from the population of abundant EGF receptors with high mobility but little direct participation in signal transduction. The latter process preferentially involves the high affinity receptor subpopulation featuring a more heterogeneous distribution and slower redistribution. That EGF-dependent signal transduction did not follow the same kinetics throughout the cell was confirmed by the time-dependent broadening of the distribution of EGFR activation. It has been shown that this process occurs solely through intramolecular or intermolecular tyrosine phosphorylation (Koland and Cerione, 1988; Honegger et al., 1990; Tartare et al., 1991). However, the observed subcellular differences in activation kinetics imply the participation of additional factors determining the speed of either the initiation or the propagation of the activated state.
Table 2. Coefficients of variation for EGF receptor recruitment, receptor activation and She translocation

\begin{tabular}{lccc}
\hline & \multicolumn{3}{c}{ Coefficient of variation } \\
\cline { 2 - 4 } Time (minutes) & EGFR recruitment & EGFR activation & Shc translocation \\
\hline 2 & 0.37 & $0.24 \pm 0.03$ & $0.65 \pm 0.09$ \\
5 & 0.41 & $0.41 \pm 0.10$ & $0.74 \pm 0.06$ \\
8 & 0.30 & $0.44 \pm 0.09$ & $0.70 \pm 0.13$ \\
20 & 0.46 & $0.49 \pm 0.16$ & $0.81 \pm 0.17$
\end{tabular}

Coefficients of variation $(\mathrm{CV})=\mathrm{s}$.d. (of activation or translation) divided by the respective means. CV and s.d. values for receptor activation and Shc translocation are from three independent experiments.

The correlation between receptor activation and Shc translocation was strongest at 5 to 8 minutes and decreased by 20 minutes. This finding reveals a time-dependent decoupling of EGFR activation and Shc translocation and points to additional mechanisms that influence the kinetics of EGFR activation and Shc translocation at later time points. Because of the impact of the local Shc concentration on the Shc signal at the microsphere, the absolute values of the correlation coefficients will tend to underestimate the correlation of receptor activation and Shc. That is, the correlation coefficients for the subpopulation of microspheres with low Shc concentration in the local environment will represent more closely the direct molecular association of receptor activation and Shc recruitment. The relative width of the Shc distributions grew by only $25 \%$, i.e. signaling coherence was preserved. The observation that the $\mathrm{CV}$ for Shc translocation and EGFR activation evolve differentially is in accordance with a timedependent decoupling of EGFR activation and Shc translocation.

\section{Concluding remarks}

The subcellular analysis of EGFR-dependent signal transduction demonstrates that the earliest molecular events already generate heterogeneity in signal transduction in a time-dependent manner. While differences in receptor subpopulations may clearly contribute to this phenomenon, a time-dependent decoupling of the different components augments the effect. The observations made for EGFRdependent signaling at the subcellular level have important implications for our general understanding of the underlying signal transduction mechanisms. Based on our observations, we propose a concept of signaling coherence to describe a signal transduction mechanism leading to a synchronized propagation of a signal at different subcellular locations or within a cell population. Our findings for the early steps in EGFR-dependent signal transduction are in contrast to the switch-like behavior of the downstream MAPK kinase cascade in this signaling pathway (Huang and Ferrell, 1996). For such a switch-like behavior, a sustained correlation as well as a decrease of the CVs would be expected. It would be worthwhile applying the method of focal EGFR stimulation (QMRA) to investigate whether subcellular heterogeneities also exist in the toggling of this switch. One is tempted to speculate that signaling coherence increases or even that activation states converge along a given signal transduction pathway. In the specific system we have addressed, the differential increase in the CVs revealed that the translocation of Shc apparently follows a more 
synchronized kinetic scheme than the preceding step(s) of EGFR activation.

In this work QMRA was employed for analysis of the kinetics of signal transduction at the subcellular level. This goal was achieved through the combination of local stimulation, preservation of cellular integrity, confocal immunofluorescence microscopy and three-dimensional image analysis. Further potential applications of QMRA include the simultaneous analysis of different signal transduction pathways applying sets of microspheres with different ligands, and the dissection of events leading to receptor activation and heterodimerizations with microspheres coated with anti-receptor monoclonal antibodies. Due to the rapid engulfment by plasma membrane and internalization, quantitative microsphere approaches are also applicable to questions for which internalization is relevant. Another interesting aspect concerns the identification of steps in a signal transduction pathway that distribute the signal throughout a cell. A microsphere-based approach for the study of integrin and cadherin signaling has been reported (Levenberg et al., 1998). The combination of QMRA with GFP fusion proteins, the strategy adopted in the present investigation, constitutes a general method for following the kinetics of protein activation and translocation at the subcellular level in vivo.

We thank Peter Verveer for helpful discussions on the image processing procedures, and Yosef Yarden for supplying numerous materials. R. B. was a recipient of a fellowship from the Studienstiftung des deutschen Volkes.

\section{REFERENCES}

Alroy, I. and Yarden, Y. (1997). The ErbB signaling network in embryogenesis and oncogenesis: signal diversification through combinatorial ligand-receptor interactions. FEBS Lett. 410, 83-86.

Baker, L. P., Chen, Q. and Peng, H. B. (1992). Induction of acetylcholine receptor clustering by native polystyrene beads, Implication of an endogenous muscle-derived signalling system. J. Cell Sci. 102, 543-555.

Blumer, K. J. and Johnson, G. L. (1994). Diversity in function and regulation of MAP kinase pathways. Trends Biochem. 19, 236-239.

Brock, R., Hamelers, I. H. L. and Jovin, T. M. (1999a). Comparison of fixation protocols for adherent cultured cells applied to a GFP fusion protein of the epidermal growth factor receptor. Cytometry 35, 353-362.

Brock, R., Vàmosi, G., Vereb, G. and Jovin, T. M. (1999b). Rapid characterization of GFP fusion proteins by intracellular fluorescence correlation microscopy (FCM). Proc. Natl. Acad. Sci. USA 96, 1012310128.

Colledge, M. and Scott, J. D. (1999). AKAPs: from structure to function. Trends Cell Biol. 9, 216-221.

Defize, L. H. K., Meisenhelder, J., Kruijer, W., Tertoolen, L. G. J., Tilly, B. C., Hunter, T., Henegouwen, P. M. P. v. B. e., Moolenaar, W. H. and Laat, S. W. d. (1989). Signal transduction by epidermal growth factor occurs through the subclass of high affinity receptors. J. Cell Biol. 109, 2495-2507.

Dezelic, G., Dezelic, N., Muic, N. and Pende, B. (1971). Latex particle agglutination in the immunochemical system human serum albumin - antihuman serum albumin rabbit serum. Eur. J. Biochem. 20, 553-560.

Egan, S. E., Giddings, B. W., Brooks, M. W., Buday, L., Sizeland, A. M. and Weinberg, R. A. (1993). Association of Sos Ras exchange protein with Grb2 is implicated in tyrosine kinase signal transduction and transformation. Nature 363, 45-51.

Emlet, D. R., Moscatello, D. K., Ludlow, L. B. and Wong, A. J. (1997). Subsets of epidermal growth factor receptors during activation and endocytosis. J. Biol. Chem. 272, 4079-4086.

Fabricant, R. N., Larco, J. E. D. and Todaro, G. J. (1977). Nerve growth factor receptors on human melanoma cells in culture. Proc. Natl. Acad. Sci. USA 74, 565-569.

Fry, D. W., Kraker, A. J., McMichael, A., Ambroso, L. A., Nelson, J. M., Leopold, W. R., Connors, R. W. and Bridges, A. J. (1994). A specific inhibitor of the epidermal growth factor receptor tyrosine kinase. Science 265, 1093-1095.

Gadella, T. W. J., Jr. and Jovin, T. M. (1995). Oligomerization of epidermal growth factor receptors on A431 cells studied by time-resolved fluorescence imaging microscopy. A stereochemical model for tyrosine kinase receptor activation. J. Cell Biol. 129, 1543-1558.

Gotoh, N., Toyoda, M. and Shibuya, M. (1997). Tyrosine phosphorylation sites at amino acids 239 and 240 of Shc are involved in epidermal growth factor-induced mitogenic signaling that is distinct from Ras/mitogenactivated protein kinase activation. Mol. Cell. Biol. 17, 1824-1831.

Gregoriou, M. and Rees, A. R. (1984). Properties of a monoclonal antibody to epidermal growth factor receptor with implications for the mechanism of action of EGF. EMBO J. 3, 929-937.

Gronowski, A. M. and Bertics, P. J. (1993). Evidence for the potentiation of epidermal growth factor receptor tyrosine kinase activity by association with the detergent-insoluble cellular cytoskeleton: Analysis of intact and carboxy-terminally truncated receptors. Endocrinology 133, 28382846.

Honegger, A. M., Schmidt, A., Ullrich, A. and Schlessinger, J. (1990). Evidence for epidermal growth (EGF)-induced intermolecular autophosphorylation of the EGF receptors in living cells. Mol. Cell. Biol. 10, 4035-4044.

Huang, C.-Y. F. and J. E. Ferrell, J. (1996). Ultrasensitivity in the mitogenactivated protein kinase cascade. Proc. Natl. Acad. Sci. USA 93, 1007810083.

Ito, Y., Chen, G. and Imanishi, Y. (1998). Micropatterned immobilization of epidermal growth factor to regulate cell function. Bioconjugate Chem. 9, 277-282.

Koland, J. G. and Cerione, R. A. (1988). Growth factor control of epidermal growth factor receptor kinase activity via an intramolecular mechanism. $J$. Biol. Chem. 263, 2230-2237.

Levenberg, S., Katz, B.-Z., Yamada, K. M. and Geiger, B. (1998). Longrange and selective autoregulation of cell-cell or cell-matrix adhesion by cadherin or integrin ligands. J. Cell Sci. 111, 347-357.

Lotti, L. V., Lanfrancone, L., Migliaccio, E., Zompetta, C., Pelicci, G., Salcini, A. E., Falini, B., Pelicci, P. G. and Torrisi, M. R. (1996). Shc proteins are localized on endoplasmatic reticulum membranes and are redistributed after tyrosine kinase receptor activation. Mol. Cell. Biol. 16, 1946-1954.

Lowry, M. B., Duchemin, A.-M., Robinson, J. M. and Anderson, C. L. (1998). Functional separation of pseudopod extension and particle internalization during Fcy receptor-mediated phagocytosis. J. Exp. Med. 187, 161-176.

Miyamoto, S., Teramoto, H., Coso, O. A., Gutkind, J. S., Burbelo, P. D., Akiyama, S. K. and Yamada, K. M. (1995). Integrin function: Molecular hierarchies of cytoskeletal and signaling molecules. J. Cell Biol. 131, 791805.

Miyamoto, S., Teramoto, H., Gutkind, J. S. and Yamada, K. M. (1996). Integrins can collaborate with growth factors for phosphorylation of receptor tyrosine kinases and MAP kinase activation: roles of integrin aggregation and occupancy of receptors. J. Cell Biol. 135, 1633-1642.

Nesterov, A., Reshetnikova, G., Vinogradova, N. and Nikolsky, N. (1990). Functional state of the epidermal growth factor-receptor complexes during their internalization in A-431 cells. Mol. Cell. Biol. 10, 5011-5014

Newton, A. C. (1996). Protein kinase C: Ports of anchor in the cell. Curr. Biol. 6, 806-809.

Olayioye, M. A., Neve, R. M., Lane, H. A. and Hynes, N. E. (2000). The ErB signaling network: receptor heterodimerization in development and cancer. EMBO J. 19, 3159-3167.

Osborn, M. and Weber, K. (1982). Immunofluorescence and immunocytochemical procedures with affinity-purified antibodies: tubulincontaining structures. Meth. Cell Biol. 24, 97-132.

Pelicci, G., Lanfrancone, L., Grignani, F., McGlade, J., Cavallo, F., Forni, G., Nicoletti, I., Grignani, F., Pawson, T. and Pelicci, P. G. (1992). A novel transforming protein (SHC) with an $\mathrm{SH} 2$ domain is implicated in mitogenic signal transduction. Cell 70, 93-104.

Peng, H. B., Baker, L. P. and Chen, Q. (1991). Induction of synaptic development in cultured muscle cells by basic fibroblast growth factor. Neuron 6, 237-246. 
Plopper, G. and Ingber, D. E. (1993). Rapid induction and isolation of focal adhesion complexes. Biochem. Biophys. Res. Comm. 193, 571-578.

Schroeder, F. and Kinden, D. A. (1983). Measurement of phagocytosis using fluorescent latex beads. J. Biochem. Biophys. Meth. 8, 15-27.

Southwick, P. L., Ernst, L. A., Tauriello, E. W., Parker, S. R., Mujumdar, R. B., Mujumdar, S. R., Clever, H. A. and Waggoner, A. S. (1990). Cyanine dye labeling reagents - Carboxymethylindocyanine succinimidyl esters. Cytometry 11, 418-430.

Tartare, S., Ballotti, R., Lammers, R., Alengrin, F., Dull, T., Schlessinger, J., Ullrich, A. and Obberghen, E. V. (1991). Insulin-EGF receptor chimerae mediate tyrosine transphosphorylation and serine/threonine phosphorylation of kinase-deficient EGF receptors. J. Biol. Chem. 266, 9900-9906.

Ullrich, A., Coussens, L., Hayflick, J. S., Dull, T. J., Gray, A., Tam, A. W., Lee, J., Yarden, Y., Libermann, T. A., Schlessinger, J., Downward, J., Mayes, E. L. V., Whittle, N., Waterfield, M. D. and Seeburg, P. H. (1984). Human epidermal growth factor receptor cDNA sequence and aberrant expression of the amplified gene in A431 epidermoid carcinoma cells. Nature 309, 418-425.
Ullrich, A. and Schlessinger, J. (1990). Signal transduction by receptors with tyrosine kinase activity. Cell 61, 203-212.

Verveer, P. J. and Jovin, T. M. (1998). Image restoration based on Good's roughness penalty with application to fluorescence microscopy. J. Opt. Soc. Am. A 15, 1077-1083.

Vieira, A. V., Lamaze, C. and Schmid, S. L. (1996). Control of EGF receptor signaling by clathrin-mediated endocytosis. Science $\mathbf{2 7 4}$, 20862089.

Voort, H. T. M. v. d. and Brakenhoff, G. J. (1990). 3-D image formation in high-aperture fluorescence confocal microscopy: a numerical analysis. $J$. Microsc. 158, 43-54.

Whitmarsh, A. J. and Davis, R. J. (1998). Structural organization of MAPkinase signaling modules by scaffold proteins in yeast and mammals. Trends Biochem. 23, 481-485.

Wiegant, F. A. C., Blok, F. J., Defize, L. H. K., Linnemans, W. A. M., Verkley, A. J. and Boonstra, J. (1986). Epidermal growth factor receptors associate to cytoskeletal elements of epidermoid carcinoma (A431) cells. $J$. Cell Biol. 103, 87-94. 